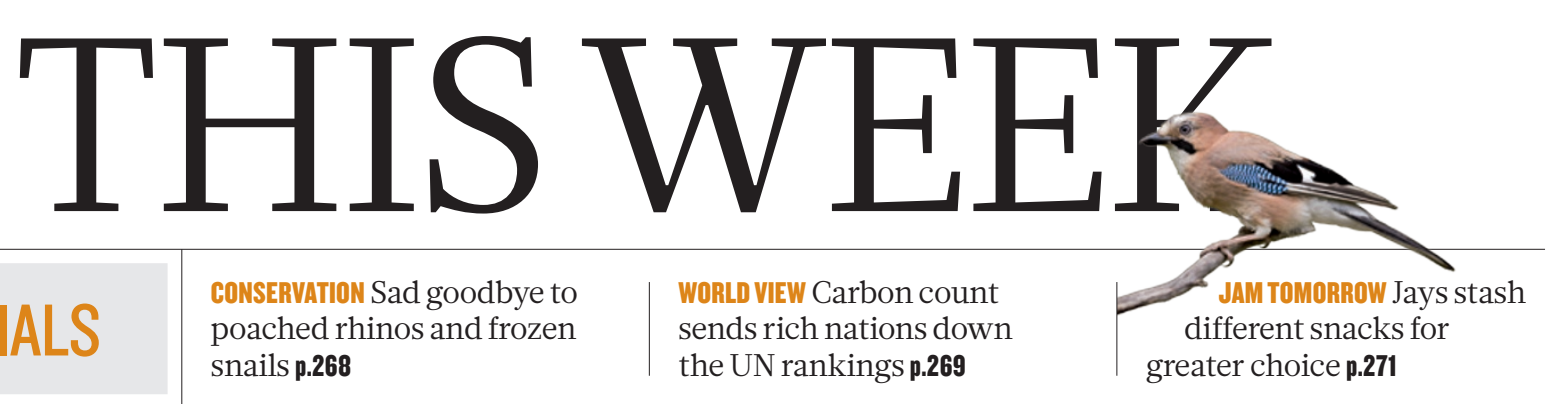

EDITORIALS snails p.268 sends rich nations down

the UN rankings $\mathbf{p . 2 6 9}$

\title{
Desirable partners
}

\section{US refusal to collaborate with China on space science is short-sighted and misguided, from both a scientific and a pragmatic standpoint.}

S pace researcher Ji Wu is invigorating space science in China. He has a new, well-funded space programme, the ear of the government and a growing list of projects. China's launch capacity is set to triple, which means that it can take the lead in the launch of increasingly large and interesting missions.

A fluent English speaker and well connected in the United States, Wu is the first Chinese vice-president of the international Committee on Space Research, a position that brings unprecedented prominence to his country's space science (see page 276).

It is a perfect opportunity for the United States to establish deeper connections with China, and the ideal time to do so. As in other fields, the Chinese follow closely what is happening in the United States and look for opportunities to collaborate and learn. With many Chinese researchers returning to China carrying experience gained from the United States or, as in Wu's case, Europe, such collaborations will become increasingly important.

But that is not what is happening. Restrictions on the interaction of US scientists with their counterparts in China have been tightened to the point at which even having meetings could be considered illegal. Led by congressman Frank Wolf (Republican, Virginia), the United States has legislated and looks set to enforce a broad ban on collaborations with China on programmes funded by the Office of Science and Technology Policy or NASA. As recent high-level legal action demonstrates, Wolf is aiming to enforce the ban even on meetings between scientists from the two countries (see Nature 478, 294-295; 2011).

Of course, it is right that the United States should be careful. There are justified fears of reverse engineering, and the country should collaborate on projects that would not put nationally sensitive technology at risk. But it should also be sensible and keep the doors of communication open. A blanket ban on sharing not just scientific missions but also ideas will hurt the United States more than China.

It can be reasonably argued that, given its dominance in space research and exploration, the United States does not currently have much to gain from collaborations with China. But that is surely a short-term situation and a dangerously short-term view. Over the next ten years there will be plenty of Chinese missions, such as the Solar Polar Orbit Radio Telescope and the KuaFu mission, both of which will study space weather, and which US scientists would love to be involved in to extend the value of their own missions. Anyway, as China showed with its successful space-docking manoeuvre this month, it can go it alone. Chinese students and space-science administrators are already following the US space science programme very closely. Through published road-map documents and scientific papers they already know, in broad brush, what is happening there.

The United States is well aware of the benefits of international collaboration in costly space science. It established NASA's Missions of Opportunity programme specifically to help its scientists use a small budget to latch on to bigger projects run by other countries - to be, as
NASA states, "part of a non-NASA space mission of any size and having a total NASA cost of under $\$ 35$ million". As budget restrictions bite, this activity will become ever more important. And the opportunities will increasingly come from China. European scientists are already building the bridges, as they did for China's Double Star mission to study Earth's magnetosphere, to move such collaborations forward.
"The United

States should

keep the doors of

communication open."
In the congressional hearings on the collaboration ban, Wolf said that the United States had "no business" cooperating with China to help it develop its space programme. "China is taking a more assertive posture globally, and their interests rarely intersect with ours," he said. Such cold-warera language is unhelpful. The perspective is worse.

By meeting with and, under strict conditions, collaborating on missions with Chinese space scientists, the United States will be able to build potentially beneficial diplomatic relations at the same time as keeping a close eye on Chinese space technology. Ultimately, in such collaborations the United States would be helping itself much more than it would help China.

\section{Climate change}

\section{Negotiations in Durban over greenhouse-gas emissions should not try to revive Kyoto.}

I n a memorable scene in Al Gore's film on global warming, An Inconvenient Truth, the former US vice-president lampoons a cartoon of a pair of scales that weighs the Earth against a stack of gold bars. Gore's point is that any attempt to compare the merits of the two is ludicrous given their relative importance in the grand scheme of things. It would be easy to satirize reports that the organizers of next year's Rio+20 Earth Summit in Brazil are considering a two-week postponement to avoid a clash with celebrations for the Diamond Jubilee of Queen Elizabeth II in the United Kingdom, which they fear will hold more appeal for politicians, particularly those from Commonwealth countries. Easy - but not necessarily wrong. If the world is to address the myriad environmental problems that scientists have identified, then at some point it will have to give them the attention and the priority they deserve. (And that comes from a journal with its headquarters just a few miles from Buckingham Palace — sorry, Ma'am.)

A good place to start would be the international negotiations on global warming that reopen in Durban, South Africa, later this month. If optimists were right to herald the tentative steps made last year in 